and Mr. Bonacina is in full agreement with the trend of modern ideas in emphasising the importance for health of frequent contrasts of weather, and especially of temperature and wind. $\mathrm{He}$ ends on a practical note by insisting that the open-air study of weather and especially clouds also makes for health by training the powers of observation and inference. Forecasts 'on tap' by wireless are a very good thing, but there are occasions, for example in mountaineering, when much discomfort or even risk might be avoided by the ability to foresee a storm an hour or two ahead.

\section{Meteorology of Southern Rhodesia}

THE annual report of the Meteorological Department of the Department of Agriculture of Southern Rhodesia for the year ended June 30, 1934, follows the general lines of previous reports (Salisbury: Department of Agriculture, 1934). In the rainy season of 1933-34, as in that of the preceding season, there was substantially less rain than usual, although the formula used for predicting the season's fall had indicated an excess of rain. During the five years for which this computation has been made, this was the first occasion on which the sign of the departure from the normal was not correctly given by the formula. An Aircraft Weather Service that had been organised for Imperial Airways operated satisfactorily during this year, and it was decided to extend the service to all aircraft. Arrangements were made to transfer the observatories at Salisbury and Bulawayo to the aerodromes, where they will be maintained by a staff of two, who will prepare regular weather reports and forecasts, and make observations of the upper winds. According to the report, the provision of an adequate weather service for aircraft is now regarded as the most important function of the Meteorological Department. The number of tables in the report has been reduced owing to financial stringency; but among those included is an interesting one showing the average $R$ hodesian rainfall for thirtysix years. In the first season, 1898-99, the fall was based on the records of seven rain-gauges, and in the most recent (1933-34), on three hundred and fortyfour.

\section{A Totalising Anemometer}

IN the Hydrographic Review, 12, No. 1, Dr. J. N. Carruthers describes a suggested totalising anemometer for oceanographers, the records of which he considers likely to be of value in climatology. Although the ordinary Robinson anemometer is a totalising instrument in so far as it registers the number of miles and fractions of a mile of air that have flowed past the anemometer in a given time, it does not distinguish between the different, wind directions, and its records can only be used for obtaining the total run in particular directions in the case of the more complicated self-registering form of this instrument that records automatically both the run and the direction, and then only after laborious calculations. In the instrument described by Dr. Carruthers, a wind vane is used which rotates a vertical rod bearing at its lower end a circular tank divided radially into eight equal compartments, each of which has a draw-off tap. A separate mast carries a 4-cup anemometer which makes and breaks an electric circuit after a certain run of wind past the cups. When the circuit is made, it energises a solenoid and the latter rocks a small pipe which is pivoted on the rim of a tank in which water is maintained at a constant level by means of an ordinary ball valve. This pipe carries a dipper which delivers a definite quantity of water through it into whichever of the eight compartments of the circular tank is beneath at the time. At the end of a period of observation, the total run of air in each of the eight directions is readily obtained by drawing off and measuring the quantity of water in each compartment.

\section{Co-ordination of Scientific Surveys}

Aт the recent meeting at Norwich of the British Association, Mr. E. Wyllie Fenton made an interesting plea, in a paper read before Section $\mathrm{K}$ (Botany), for the extension and co-ordination of the existing Ordnance and Geological Surveys into a wide body to carry out periodic surveys not only of topography, rocks and soils but also of vegetation, agriculture and animal life. Mr. Wyllie Fenton's illustrations of the wider need were mainly botanical, as for example, the invasion of valuable land in Scotland by bracken moving downhill to the better land "like a series of plant glaciers", and the association of this fact with changes in land settlement and agricultural practice. A plea was advanced for a prompter recognition of these significant changes in vegetation and in the results of changes in population. distribution, etc., with the argument that a more scientific utilisation of the land, in housing development, in agriculture and in forestry, etc., would be possible if such a general scientific survey service provided the data. Mr. Fenton recognises, however, the ambitious nature of such a proposal, and suggests that a start might be made by the attachment of a few botanists to the Geological Survey.

\section{Metals in the Chemical Industry}

IN his Jubilee Memorial Lecture of the Society of Chemical Industry delivered before the Yorkshire Section at Leeds on November 6, Dr. C. H. Desch took as his subject "Metals in the Chemical Industry". The range of both ferrous and non-ferrous metals available for the purposes of chemical industry has been immensely widened in recent years. Resistance to chemical attack is one of the first considerations, and as no one material is resistant to all chemical agents, a choice must be made in each instance, for which ample data now exist. Corrosion fatigue, caused by the simultaneous action of fluctuating stress and of a chemical agent, is quite different from the sum of the actions of fatigue and corrosion, and is responsible for many unexpected failures. Special conditions arise where high temperatures and pressures are involved. Resistance to 'creep' is required as well as chemical resistance, and internal changes may cause progressive weakening. Not only chemical 